\title{
Special issue: Application of beneficial microorganisms and their effects on soil, plants, and the environment. The scientific legacy of Professor Yoav Bashan
}

(C) Springer-Verlag GmbH Germany, part of Springer Nature 2020

The following articles are part of the Special Issue "Application of beneficial microorganisms and their effects on soil, plants, and the environment. The scientific legacy of Professor Yoav Bashan" Guest Edited by Luz E. de-Bashan, Hani Antoun, Robert Lindermann and were inadvertently published in a different issue:

"Seed inoculation with Penicillium bilaiae and Bacillus simplex affects the nutrient status of winter wheat"

Hansen, V., Bonnichsen, L., Nunes, I. et al. Biol Fertil Soils 56, 97-109 (2020). https://doi.org/10.1007/s00374019-01401-7
"Open field inoculation with PGPR as a strategy to manage fertilization of ancient Triticum genotypes"

Pagnani, G., Galieni, A., Stagnari, F. et al. Biol Fertil Soils 56, 111-124 (2020). https://doi.org/10.1007/s00374-01901407-1

"Polymer-coated rock mineral fertilizer has potential to substitute soluble fertilizer for increasing growth, nutrient uptake, and yield of wheat"

Assainar, S.K., Abbott, L.K., Mickan, B.S. et al. Biol Fertil Soils 56, 381-394 (2020). https://doi.org/10.1007/s00374019-01428-w 